\title{
DESEMPENHO COMPARATIVO ENTRE DUAS LINHAGENS DE ROEDEIRAS COMERCIAIS DEBICADAS EM DIFERENTES IDADES NA FASE DE RECRIA ${ }^{1}$
}

\author{
COMPARATIVE PERFORMANCE BETWEEN TWO COMMERCIAL LAYING HEN \\ STRAINS BEAK TRIMMED AT DIFFERENT AGES ON GROWING PHASE
}

\author{
Pedro Kikuo Oda ${ }^{2}$ Vera Maria Barbosa de Moraes ${ }^{3}$ Joji Ariki $^{4}$ \\ Ramon Diniz Malheiros ${ }^{5}$ Renato Luís Furlan ${ }^{6}$ Sérgio do Nascimento Kronka ${ }^{7}$
}

RESUMO

O experimento foi realizado com o objetivo de comparar o desempenho produtivo de duas linhagens comerciais de poedeiras debicadas em diferentes idades na fase de recria. Foram utilizadas 250 aves da linhagem Lohmann (LSL) e 250 aves da linhagem Isa Babcock (IB), debicadas em diferentes idades. A primeira debicagem foi realizada no $8^{a}$ dia de idade e a segunda na $8^{\circ}, 10^{\circ}, 12^{a}$ ou $14^{\circ}$ semana de idade. Um grupo de 32 aves permaneceu com o bico intacto e outro não foi submetido à segunda debicagem. $O$ delineamento utilizado foi em blocos ao acaso, em esquema fatorial $2 x 6$ (linhagens $x$ idade de debicagem). Não foi verificado efeito significativo da idade de debicagem sobre os parâmetros produtivos analisados, exceto a melhoria significativa na produção de ovos. As aves da linhagem LSL apresentaram melhores resultados para maturidade sexual, peso médio dos ovos, produção de ovos/ave dia, porcentagem de ovos quebrados e conversão alimentar, quando comparadas às aves da linhagem IB. Embora a prática da debicagem tenha melhorado a porcentagem de postura, os resultados evidenciaram que os parâmetros produtivos analisados foram mais influenciados pela linhagem do que pela idade de debicagem.

Palavras-chave: debicagem, desempenho, linhagens, peso corporal.

SUMMARY

The present experiment was conducted to compare the performance between two commercial laying hens strains beak trimmed at different ages during growing phase. Two hundred andfifty birds ofLohmam (LSL.) stram anã two hundred andfifty birds of Isa Babcock (IB) stram were beak trimmed at dijferent ages. Thefirst trimmed was accomplished in the $S^{l}$ day of age and second one at $\mathrm{S}^{\prime *}, 10^{\prime \prime \prime}, 12^{\prime \prime}$ or 14"' week of age. A group of 32 birds from each strain was left with beaks intact and the other was not submitted to the second beak trimmed. The data were analyzed as $2 \times 6$ (stram $x$ beak trimmimg age) factorial arrangement $m$ a randomised block design. The produclive parameters studied were not significantiy affected by beak trimming age, except the egg production. The LSL strain showed better results for sexual maturity, egg weight, egg production, percentage of broken eggs and feed conversion than IB strain. The results revealed that analywd productive performance were more influenced by laying stram than beak trimming age. The relative benefits of beak trimming could vary among laying strains.

Key words: beak trimming, body weight, performance, strains.

\section{INTRODUÇÃO}

Apesar do indiscutível progresso alcançado na avicultura, muitas técnicas de manejo adotadas atualmente são as mesmas empregadas há vários anos, exigindo reavaliações, como é o caso da debicagem em poedeiras. A literatura mostra a necessidade de se realizar a debicagem devido à redução do canibalismo (LEE, 1980), pelo efeito benéfico no consumo de ração (CRAIG et al., 1992),

\footnotetext{
${ }^{1}$ Trabalho de graduação apresentado à Faculdade de Ciências Agrárias e Veterinárias (FCAV), UNESP de Jaboticabal.

${ }^{2}$ Zootecnista formado na FCAV-UNESP, Jaboticabal.

${ }^{3}$ Professora Assistente, Doutor, Departamento de Zootecnia, Faculdade de Ciências Agrárias e Veterinárias UNESP, 14870-000, Jaboticabal, SP, Brasil. E-mail: vbmoraes@ fcav.unesp.br. Autor para correspondência.

${ }^{4}$ Professor Titular, Departamento de Zootecnia, FCAV-UNESP, Jaboticabal.

${ }^{5}$ Doutorando da FCAV-UNESP, Departamento de Morfologia e Fisiologia Animal.

${ }^{6}$ Professor Assistente, Doutor, Departamento de Morfologia e Fisologia Animal, FCAV-UNESP, Jaboticabal.

${ }^{7}$ Professor Titular, Departamento de Ciências Exatas, FCAV-UNEP, Jaboticabal.
} 
melhora na conversão alimentar (LEE \& CRAIG, 1990) e diminuição da mortalidade das aves (LEE \& CRAIG, 1991).

Atualmente, existem muitas controvérsias com relação à idade da debicagem em frangas. Os manuais de manejo das linhagens comerciais ISA BABCOCK (1990) e LOHMANN (sd) recomendam duas debicagens. A primeira entre 6 e 10 dias de idade e a segunda entre 6 e 8 semanas para Isa Babcock (IB) e 13 e 15 semanas de idade para a Lohmann (LSL). WELLS (1983) sugeriu a realização da debicagem aos 5 ou 10 dias ou com 10 a 12 semanas de idade. Já GENTLE (1986) mostrou a ocorrência de grande dificuldade em se manipular a ave jovem devido ao tamanho reduzido do bico, no qual os danos causados pela lâmina aumentam a variabilidade da quantidade de tecido removido. Em aves mais velhas, essa quantidade de tecido pode ser facilmente controlada, mas o estresse envolvido é muito grande. GENTLE et al. (1997) recomendam, se houver necessidade da debicagem em aves jovens, que seja feita, de preferência, com um dia de idade. No entanto, CAREY \& LASSITER (1995), debicando aves no $10^{\circ}, 10^{\circ}$ e $64^{\circ}$ ou $10^{\circ}$ e $84^{\mathrm{a}}$ dia de idade, não observaram efeito significativo da idade da debicagem sobre os parâmetros produtivos de poedeiras comerciais.

Recentes estudos também levantam a dúvida da real necessidade da debicagem em determinadas linhagens, pelas evidentes diferenças no comportamento entre linhagens, principalmente, no que diz respeito à incidência de bicagem de penas e canibalismo. BECKMAN (1994) e MUIR \& CRAIG(1998) reportaram a existência de linhagens que requerem um mínimo ou nenhuma debicagem, sem promover qualquer prejuízo na produtividade. Em contraste, muitos técnicos da indústria avícola recomendam a debicagem como prática indispensável.

O objetivo deste estudo foi avaliar o desempenho produtivo de duas linhagens de poedeiras comerciais, consideradas de comportamento diferentes, debicadas em diferentes idades na fase de recria.

\section{MATERIAL E MÉTODOS}

Foram utilizados 250 pintos da linhagem Lohmann (LSL), conhecida por possuir um temperamento calmo e 250 da linhagem Isa Babcock (IB), com temperamento um pouco mais agressivo. Até a $8^{\mathrm{a}}$ semana os pintos foram criados em piso com cama de maravalha, com água e ração à vontade, sendo, em seguida, transferidos para o galpão de recria, e alojados em grupos de oito aves em gaiolas de $0,50 \times 0,50 \times 0,40 \mathrm{~m}$ de altura. Ao final da $16^{\mathrm{a}}$ semana de idade, as aves foram transferidas para o galpão de postura, sendo colocadas duas aves por gaiola de $0,25 \times 0,40 \times 0,40 \mathrm{~m}$.

A primeira debicagem foi realizada com oito dias de idade, mantendo 32 pintos de cada linhagem com o bico intacto (testemunha) durante todo o experimento. A segunda debicagem ocorreu na $8^{\mathrm{a}}, 10^{\mathrm{a}}, 12^{\mathrm{a}}$ ou $14^{\mathrm{a}}$ semana, em que um grupo de 32 frangas de cada linhagem permaneceu sem a segunda debicagem. As debicagens foram realizadas cuidadosamente em um debicador (Lyon) com lâmina quente convencional. $\mathrm{Na}$ primeira debicagem, os bicos superior e inferior foram cortados simultaneamente. Na segunda debicagem primeiro foi cortado o bico superior e, em seguida, o inferior, procurando cauterizar bem os cantos, obtendo um corte em V.

Os parâmetros avaliados foram: idade à maturidade sexual ( $5 \%$ de postura), produção e pesodos ovos, consumo diário de ração, conversão alimentar (consumo/dz e kg de ovos) e porcentagem de ovos quebrados, do início de produção até 40 semanas de idade.

As rações à base de milho e farelo de soja foram formuladas utilizando as tabelas de composição de ingredientes e exigências nutricionais de ROSTAGNO et al. (1987), de forma a conterem 18 e $2.900,17$ e 2.700 e $18 \%$ de proteína bruta e $2.800 \mathrm{kcal} \mathrm{EM} / \mathrm{kg}$ de ração, para as fases de cria, recria e postura, respectivamente. O programa de luz adotado foi o natural até o início da maturidade sexual e, em seguida, luz artificial com aumentos graduais, até atingir 17 horas por dia (natural + artificial), coincidindo com a época prevista para o pico de produção. O esquema de vacinação foi realizado conforme os manuais de cada linhagem.

Foi utilizado o delineamento experimental em blocos ao acaso, em esquema fatorial $2 \times 6$ (linhagens $\mathrm{x}$ idades de debicagem), com quatro repetições e 8 e 6 aves por parcela nas fases de recria e postura, respectivamente. Os resultados foram submetidos à análise de variância de acordo com BANZATTO \& KRONKA (1995) e as médias comparadas pelo teste de Tukey em nível de $5 \%$ de probabilidade.

\section{RESULTADOS E DISCUSSÃO}

Os dados da tabela 1 mostram que as aves da linhagem Isa Babcock tiveram uma menor ingestão de alimento $(\mathrm{P}<0,01)$ em todas as idades analisadas. Já a debicagem exerceu efeito significativo $(\mathrm{P}<0,01)$ sobre o consumo de ração, sendo observado uma redução no consumo de ração imediatamente após a debicagem até a $16^{\text {a }}$ semana. CRAIG et al. (1992) também haviam verificado um decréscimo no 
Tabela 1 - Valores do teste F, coeficiente de variação e médias de consumo de ração (g/ave/dia) em galinhas de duas linhagens comerciais de poedeiras submetidas ou não à debicagem de acordo com as idades.

\begin{tabular}{|c|c|c|c|c|c|c|c|c|c|}
\hline \multirow{2}{*}{ FATORES } & \multicolumn{9}{|c|}{ Idade (semana) } \\
\hline & 10 & 12 & 14 & 16 & 18 & 20 & Recria $^{1}$ & 40 & Postura $^{2}$ \\
\hline \multicolumn{10}{|l|}{ LINHAGENS (L): } \\
\hline Lohmann & 63,94 & 64,25 & 76,30 & 77,50 & 71,10 & 76,90 & 3.740 & 109,9 & 15.880 \\
\hline Isa Babcock & 55,69 & 59,05 & 70,90 & 72,60 & 66,20 & 72,50 & 3.460 & 105,0 & 15.130 \\
\hline \multicolumn{10}{|l|}{ DEBICAGENS } \\
\hline Sem debicagens (Testem.) & $61,62^{\mathrm{a} 3}$ & 64,50 & $76,50^{\mathrm{a}}$ & 76,60 & 70,00 & 75,90 & 3.740 & 111,7 & 15.860 \\
\hline Sem a $2^{\mathrm{a}}$ debicagem & $60,87^{\mathrm{a}}$ & 62,50 & $75,50^{\mathrm{a}}$ & 77,40 & 70,40 & 74,10 & 3.690 & 106,1 & 15.270 \\
\hline $2^{\mathrm{a}}$ debicagem na $8^{\mathrm{a}}$ semana & $56,75^{\mathrm{b}}$ & 60,30 & $73,40^{\mathrm{a}}$ & 74,00 & 67,60 & 74,60 & 3.540 & 105,5 & 15.410 \\
\hline $2^{\mathrm{a}}$ debicagem na $10^{\mathrm{a}}$ semana & $60,12^{\mathrm{ab}}$ & 58,80 & $73,10^{\mathrm{a}}$ & 77,80 & 69,00 & 75,90 & 3.610 & 108,9 & 15.700 \\
\hline $2^{\mathrm{a}}$ debicagem na $12^{\mathrm{a}}$ semana & --- & 62,30 & $67,80^{\mathrm{b}}$ & 76,50 & 66,50 & 72,80 & 3.550 & 104,3 & 15.240 \\
\hline $2^{\mathrm{a}}$ debicagen na $14^{\mathrm{a}}$ semana & --- & --- & $75,00^{\mathrm{a}}$ & 68,00 & 68,60 & 75,00 & 3.470 & 108,3 & 15.560 \\
\hline \multicolumn{10}{|l|}{ VALORES DO TESTE F: } \\
\hline LINHAGENS (L) & $73,12^{* *}$ & $54,89^{* *}$ & $38,56^{* *}$ & $38,15^{* *}$ & $18,77 * *$ & $7,69 * *$ & $82,23^{*}$ & $6,02 *$ & $12,71^{*}$ \\
\hline DEBICAGENS (D) & $5,25 * *$ & $7,95 * *$ & $8,37 * *$ & $14,32 * *$ & $1,11^{\mathrm{ns}}$ & $0,38^{\mathrm{ns}}$ & $7,16^{* *}$ & $1,17^{\mathrm{ns}}$ & $0,88^{\mathrm{ns}}$ \\
\hline INTERAÇÃO (LXD) & $2,99^{\mathrm{ns}}$ & $6,48 * *$ & $1,34^{\mathrm{ns}}$ & $4,58 * *$ & $2,61 *$ & $0,38^{\mathrm{ns}}$ & $4,99 * *$ & $0,49^{\mathrm{ns}}$ & $0,51^{\mathrm{ns}}$ \\
\hline CV $(\%)$ & 4,56 & 3,60 & 4,08 & 3,67 & 5,67 & 4,07 & 3,05 & 6,51 & 4,78 \\
\hline
\end{tabular}

${ }^{1}$ Fase total da recria (57 a 114 dias). ${ }^{2}$ Fase total da postura (115 a 280 dias). ${ }^{3}$ Médias seguidas de letras iguais nas colunas não diferem entre si $(\mathrm{P}>0,05)$ pelo teste de Tukey.

$* *$ Significado $(\mathrm{P}<0,01)$. *Significado $(\mathrm{P}>0,05)$ ns - Não significativo.

consumo de ração até 35 semanas de idade para aves debicadas duas vezes, em relação às aves não debicadas e debicadas uma vez. Esses resultados podem estar relacionados ao efeito estressante da debicagem. Experimentos fisiológicos têm mostrado que a dor associada à debicagem persiste por muitas semanas após a operação (LEE \& CRAIG, 1990 e 1991). Anteriormente, BREWARD \& GENTLE (1985) haviam verificado a ocorrência de neuromas nos bicos, aumentando a atividade nervosa espontânea, provocando a síndrome da dor. Segundo GENTLE (1986), a debicagem causa estresse, entretanto, é uma prática recomendada e desejada, desde que realizada com cuidado.

Não foi observado efeito $(\mathrm{P}>0,05)$ da debicagem sobre o consumo de ração durante o período de postura mas, ocorreu interação significativa entre linhagens e debicagens na $12^{\mathrm{a}}$, $16^{\mathrm{a}}, 18^{\mathrm{a}}$ semana e período total de recria. A interação (Tabela 2) mostra que, no período total de recria, as aves da linhagem LSL reduziram o consumo de alimento após a debicagem, cujo efeito não foi observado nas aves da linhagem IB.

Com relação ao peso vivo médio das aves, a análise de variância mostrou existir interação significativa $(P<0,05)$ entre linhagem e debicagem nas idades de 10, 12, 14 e 16 semanas; no entanto, não houve interação significativa na $8^{\mathrm{a}}$ e na $40^{\mathrm{a}}$ semana (Tabela3). Os resultados da interação (Tabela 4) revelam que as aves da linhagem Lohmann
Tabela 2 - Desdobramento da interação entre linhagens e idade de debicagem sobre o consumo de ração (g/ave/dia).

\begin{tabular}{|c|c|c|c|}
\hline \multirow{2}{*}{$\begin{array}{c}\text { Idade } \\
\text { (semanas) }\end{array}$} & \multirow{2}{*}{ Debicagem } & \multicolumn{2}{|c|}{ Linhagem } \\
\hline & & Lohmann & $\begin{array}{c}\text { Isa } \\
\text { Babcock }\end{array}$ \\
\hline \multirow{7}{*}{12} & Sem debicagem & $70,30^{\mathrm{A} \text { al }}$ & $58,80^{\mathrm{Aa}}$ \\
\hline & Sem $2^{\mathrm{a}}$ debicagem & $65,80^{\mathrm{A} a b}$ & $59,30^{\mathrm{Ba}}$ \\
\hline & $2^{\mathrm{a}}$ debicagem na $8^{\mathrm{a}}$ semana & $62,30^{\mathrm{A} \mathrm{bc}}$ & $58,30^{\mathrm{B} \mathrm{a}}$ \\
\hline & $2^{\mathrm{a}}$ debicagem na $10^{\mathrm{a}}$ semana & $59,50^{\mathrm{A} \mathrm{a}}$ & $58,00^{\mathrm{A} \mathrm{a}}$ \\
\hline & $2^{\mathrm{a}}$ debicagem na $12^{\mathrm{a}}$ semana & $63,50^{\mathrm{Abc}}$ & $61,00^{\mathrm{Aa}}$ \\
\hline & $2^{\mathrm{a}}$ debicagem na $14^{\mathrm{a}}$ semana & --- & --- \\
\hline & Sem debicagem & $81,00^{\mathrm{Aa}}$ & $72,20^{\mathrm{B} b c}$ \\
\hline \multirow{5}{*}{16} & Sem $2^{\mathrm{a}}$ debicagem & $82,30^{\mathrm{Aa}}$ & $72,50^{\mathrm{B} b c}$ \\
\hline & $2^{\mathrm{a}}$ debicagem na $8^{\mathrm{a}}$ semana & $77,00^{\mathrm{A} \mathrm{a}}$ & $71,00^{\mathrm{B} \mathrm{bc}}$ \\
\hline & $2^{\mathrm{a}}$ debicagem na $10^{\mathrm{a}}$ semana & $77,00^{\mathrm{A} \mathrm{a}}$ & $78,50^{\mathrm{A} \mathrm{a}}$ \\
\hline & $2^{\mathrm{a}}$ debiacagem na $12^{\mathrm{a}}$ semana & $78,50^{\mathrm{A} \mathrm{a}}$ & $74,50^{\mathrm{B} \text { ab }}$ \\
\hline & $2^{\mathrm{a}}$ debicagem na $14^{\mathrm{a}}$ semana & $69,30^{\mathrm{Ab}}$ & $66,80^{\mathrm{Ac}}$ \\
\hline \multirow{6}{*}{18} & Sem debicagem & $75,30^{\mathrm{Aa}}$ & $64,80^{\mathrm{Ba}}$ \\
\hline & Sem $2^{\mathrm{a}}$ debicagem & $74,30^{\mathrm{A} \mathrm{a}}$ & $66,50^{\mathrm{Ba}}$ \\
\hline & $2^{\mathrm{a}}$ debicagem na $8^{\mathrm{a}}$ semana & $69,50^{\mathrm{Aa}}$ & $65,80^{\mathrm{A} a}$ \\
\hline & $2^{\mathrm{a}}$ debicagem na $10^{\mathrm{a}}$ semana & $67,80^{\mathrm{Aa}}$ & $70,30^{\mathrm{Aa}}$ \\
\hline & $2^{\mathrm{a}}$ debiacagem na $12^{\mathrm{a}}$ semana & $68,30^{\mathrm{A} a}$ & $64,80^{\mathrm{Aa}}$ \\
\hline & $2^{\mathrm{a}}$ debicagem na $14^{\mathrm{a}}$ semana & $71,80^{\mathrm{A} \mathrm{a}}$ & $65,50^{\mathrm{Ba}}$ \\
\hline \multirow{6}{*}{ Recria $^{2}$} & Sem debicagem & $4.010^{\mathrm{Aa}}$ & $3.480^{\mathrm{Ba}}$ \\
\hline & Sem $2^{\mathrm{a}}$ debicagem & $3.900^{\mathrm{A} a b}$ & $3.490^{\mathrm{Ba}}$ \\
\hline & $2^{a}$ debicagem na $8^{a}$ semana & $3.730^{\mathrm{A} \mathrm{bc}}$ & $3.350^{\mathrm{Ba}}$ \\
\hline & $2^{\mathrm{a}}$ debicagem na $10^{\mathrm{a}}$ semana & $3.670^{\mathrm{Abc}}$ & $3.560^{\mathrm{Aa}}$ \\
\hline & $2^{\mathrm{a}}$ debiacagem na $12^{\mathrm{a}}$ semana & $3.630^{\mathrm{Ac}}$ & $3.480^{\mathrm{Aa}}$ \\
\hline & $2^{\mathrm{a}}$ debicagem na $14^{\mathrm{a}}$ semana & $3.540^{\mathrm{Ac}}$ & $3.390^{\mathrm{Aa}}$ \\
\hline
\end{tabular}

1 - Médias seguidas de letras iguais, maiúsculas nas linhas e minúsculas nas colunas, não diferem entre si $(\mathrm{P}>0,05)$ pelo teste de Tukey.

2 - Fase total da Recria (57 a 114 dias) 
Tabela 3 - Valores do teste F, coeficiente de variação e médias de peso vivo (g/ave/dia) em galinhas de duas linhagens comerciais de poedeira submetidas ou não à debicagem de acordo com as idades.

\begin{tabular}{|c|c|c|c|c|c|c|}
\hline & \multicolumn{6}{|c|}{ Idade (semana) } \\
\hline & 8 & 10 & 12 & 14 & 16 & 40 \\
\hline \multicolumn{7}{|l|}{ LINHAGENS (L) } \\
\hline Lohmann & 579,20 & 837,30 & 986,00 & $1.098,80$ & $1,255,80$ & $1.780,00$ \\
\hline Isa Babcock & 502,20 & 738,40 & 904,50 & $1.022,10$ & $1.157,50$ & $1.710,00$ \\
\hline \multicolumn{7}{|l|}{ DEBICAGENS (D): } \\
\hline Sem debicagem (Testem.) & $594,50^{\mathrm{a}}$ & 825,10 & 996,30 & $1.116,30$ & $1.258,80$ & $1.770,00$ \\
\hline Sem $2^{\text {a }}$ debicagem & $563,50^{\mathrm{B}}$ & 793,10 & 956,30 & $1.073,80$ & $1.217,50$ & $1.720,00$ \\
\hline $2^{\mathrm{a}}$ debicagem na $8^{\mathrm{a}}$ semana & $549,30^{\mathrm{B}}$ & 755,70 & 923,80 & $1.046,30$ & $1.197,50$ & $1.730,00$ \\
\hline $2^{\mathrm{a}}$ debicagem na $10^{\mathrm{a}}$ semana & --- & 776,60 & 933,80 & $1.055,00$ & $1.211,30$ & $1.730,00$ \\
\hline $2^{\mathrm{a}}$ debicagem na $12^{\mathrm{a}}$ semana & --- & --- & 928,80 & $1.033,80$ & $1.201,30$ & $1.720,00$ \\
\hline $2^{\mathrm{a}}$ debicagem na $14^{\mathrm{a}}$ semana & --- & --- & --- & $1.037,50$ & $1.153,80$ & $1.770,00$ \\
\hline \multicolumn{7}{|l|}{ VALORES DO TESTE F: } \\
\hline LINHAGEM (L) & $236,17 * *$ & $132,76 * *$ & $72,12 * *$ & $60,60 * *$ & $63,39 * *$ & $8.51 * *$ \\
\hline DEBICAGENS (D) & $10,75^{* *}$ & $11,70^{* *}$ & $7,53 * *$ & $6,54^{*}$ & $5,11^{* *}$ & $0.65^{\mathrm{NS}}$ \\
\hline INTERAÇÃO (LXD) & $1,38^{\mathrm{NS}}$ & $6,62 * *$ & $7,23 * *$ & $5,34 * *$ & $2,84^{*}$ & $0,99^{\mathrm{NS}}$ \\
\hline CV $(\%)$ & 3,50 & 3,07 & 3,21 & 3,21 & 3,51 & 4,85 \\
\hline
\end{tabular}

Médias seguidas de letras iguais nas colunas não diferem en tre si $(\mathrm{P}>0,05)$ pelo teste de Tukey;

** Significativo $(\mathrm{P}<0,01)$. $\quad *$ Significativo $(\mathrm{P}>0,05) \quad$ NS - não sigficativo

Tabela 4 - Desdobramento da interação entre linhagens e idade de debicagem sobre o peso médio das aves $(\mathrm{g})$.

\begin{tabular}{|c|c|c|c|}
\hline & \multirow{2}{*}{ Debicagem } & \multicolumn{2}{|c|}{ Linhagem } \\
\hline & & Lohmann & $\begin{array}{c}\text { Isa } \\
\text { Babcock }\end{array}$ \\
\hline \multirow{6}{*}{10} & Sem debicagem & $896^{\mathrm{Aa} 1}$ & $755^{\mathrm{B} \mathrm{a}}$ \\
\hline & Sem $2^{\mathrm{a}}$ debicagem & $852^{\mathrm{A} a b}$ & $736^{\mathrm{B} \text { a }}$ \\
\hline & $2^{\mathrm{a}}$ debicagem na $8^{\mathrm{a}}$ semana & $807^{\mathrm{A} \mathrm{bc}}$ & $705^{\text {B b }}$ \\
\hline & $2^{\mathrm{a}}$ debicagem $10^{\mathrm{a}}$ semana & $795^{\mathrm{Ac}}$ & $758^{\mathrm{B} \text { a }}$ \\
\hline & $2^{\mathrm{a}}$ debicagem $12^{\mathrm{a}}$ demana & --- & --- \\
\hline & $2^{\mathrm{a}}$ debicagem $14^{\mathrm{a}}$ semana & --- & --- \\
\hline \multirow{6}{*}{12} & Sem debicagem & $1.077^{\mathrm{Aa}}$ & $915^{\mathrm{B} \mathrm{a}}$ \\
\hline & Sem $2^{\mathrm{a}}$ debicagem & $996^{\mathrm{Aab}}$ & $893^{\text {B a }}$ \\
\hline & $2^{\mathrm{a}}$ debicagem na $8^{\mathrm{a}}$ semana & $968^{\mathrm{Abc}}$ & $880^{\mathrm{B} \text { a }}$ \\
\hline & $2^{\mathrm{a}}$ debicagem $10^{\mathrm{a}}$ semana & $955^{\mathrm{Abc}}$ & $813^{\mathrm{Aa}}$ \\
\hline & $2^{\mathrm{a}}$ debicagem $12^{\mathrm{a}}$ demana & $935^{\mathrm{Ac}}$ & $923^{\mathrm{A} a}$ \\
\hline & $2^{\mathrm{a}}$ debicagem $14^{\mathrm{a}}$ semana & --- & --- \\
\hline \multirow{6}{*}{14} & Sem debicagem & $1.188^{\mathrm{Aa}}$ & $1.045^{\mathrm{B} \mathrm{a}}$ \\
\hline & Sem $2^{\mathrm{a}}$ debicagem & $1.145^{\mathrm{Aab}}$ & $1.003^{\mathrm{Ba}}$ \\
\hline & $2^{\mathrm{a}}$ debicagem na $8^{\mathrm{a}}$ semana & $1.088^{\mathrm{Abc}}$ & $1.005^{\mathrm{B} \mathrm{a}}$ \\
\hline & $2^{\mathrm{a}}$ debicagem $10^{\mathrm{a}}$ semana & $1.073^{\mathrm{Abc}}$ & $1.038^{\mathrm{Aa}}$ \\
\hline & $2^{\mathrm{a}}$ debicagem $12^{\mathrm{a}}$ demana & $1.040^{\mathrm{Ac}}$ & $1.028^{\mathrm{Aa}}$ \\
\hline & $2^{\mathrm{a}}$ debicagem $14^{\mathrm{a}}$ semana & $1.060^{\mathrm{Ac}}$ & $1.015^{\mathrm{Aa}}$ \\
\hline \multirow{6}{*}{16} & Sem debicagem & $1.325^{\mathrm{A} \mathrm{a}}$ & $1.175^{\mathrm{B} \mathrm{a}}$ \\
\hline & Sem $2^{\mathrm{a}}$ debicagem & $1.293^{\mathrm{Aab}}$ & $1.143^{\mathrm{B} \mathrm{a}}$ \\
\hline & $2^{\mathrm{a}}$ debicagem na $8^{\mathrm{a}}$ semana & $1.248^{\mathrm{Abc}}$ & $1.148^{\mathrm{B} \mathrm{a}}$ \\
\hline & $2^{\mathrm{a}}$ debicagem $10^{\mathrm{a}}$ semana & $1.235^{\mathrm{Abc}}$ & $1.188^{\mathrm{Aa}}$ \\
\hline & $2^{\mathrm{a}}$ debicagem $12^{\mathrm{a}}$ demana & $1.238^{\mathrm{Abc}}$ & $1.165^{\mathrm{B} \mathrm{a}}$ \\
\hline & $2^{\mathrm{a}}$ debicagem $14^{\mathrm{a}}$ semana & $1.180^{\mathrm{Ac}}$ & $1.128^{\mathrm{Aa}}$ \\
\hline
\end{tabular}

1 - Médias seguidas de letras iguais, maiúsculas nas linhas e minúsculas nas colunas, não diferem entre si $(\mathrm{P}>0,05)$ pelo teste de Tukey. apresentaram peso vivo médio significativamente maior do que as aves da linhagem Isa Babcock, independente se as aves haviam sido ou não debicadas. Com relação ao efeito da debicagem, ocorreu uma redução no peso vivo após a debicagem nas aves da linhagem Lohmann; no entanto, esSe efeito não foi observado nas aves da linhagem Isa Babcock (Tabela 4). LEE \& CRAIG (1991) verificaram que aves debicadas ao final da fase de recria apresentavam redução no ganho de peso corporal. Trabalho de MORENO (1994) também mostrou que durante o período de recria, aves não debicadas, ou debicadas apenas uma vez, apresentaram peso vivo maior do que aves debicadas três vezes. BELL (1996) reportou que aves não debicadas apresentaram maior peso corporal nas oito primeiras semanas de postura. Portanto, o menor peso vivo observado nas aves da linhagem Lohmann, após a debicagem, foi provavelmente uma resposta à redução na ingestão de alimento.

$\mathrm{Na}$ fase de postura (Tabela 5), não houve diferença significativa $(\mathrm{P}>0,05)$ nos resultados de porcentagem de postura e conversão alimentar $(\mathrm{kg} / \mathrm{dz})$ entre as linhagens envolvidas. As aves da linhagem LSL atingiram a maturidade sexual mais cedo $(\mathrm{P}<0,01)$, produziram ovos mais pesados $(\mathrm{P}<0,01)$, tiveram menor porcentagem de ovos quebrados $(\mathrm{P}<0,05)$ e apresentaram melhor $(\mathrm{P}<0,05)$ conversão alimentar (kg/kg), quando comparadas com as aves da linhagem IB. Na 
Tabela 5 - Valores do teste $\mathrm{F}$, coeficiente de variação e médias de desempenho produtivo em galinhas de duas linhagens comerciais submetidas ou não à debicagem em diferentes idades avaliadas no início de produção até 40 semanas de idade.

\begin{tabular}{|c|c|c|c|c|c|c|c|}
\hline FATORES & $\begin{array}{c}\text { Idade aos } \\
5 \% \\
\text { de postura }\end{array}$ & $\begin{array}{c}\text { Peso médio } \\
\text { dos ovos } \\
(\mathrm{g})\end{array}$ & $\begin{array}{l}\% \text { média } \\
\text { de postura }\end{array}$ & $\begin{array}{l}\mathrm{N}^{\circ} \text { de ovos } \\
\text { produzidos }\end{array}$ & $\begin{array}{c}\text { Ovos } \\
\text { quebrados }{ }^{1} \\
(\%)\end{array}$ & $\begin{array}{c}\text { Conversão } \\
\text { alimentar } \\
(\mathrm{kg} / \mathrm{kg})\end{array}$ & $\begin{array}{c}\text { Conversão } \\
\text { alimentar } \\
(\mathrm{kg} / \mathrm{dz})\end{array}$ \\
\hline \multicolumn{8}{|l|}{ LINHAGENS (L): } \\
\hline Lohmann & 124,00 & 54,75 & 85,47 & 131,29 & 3,66 & 2,13 & 1,39 \\
\hline Isa Babcock & 130,25 & 53,10 & 85,02 & 123,00 & 4,60 & 2,22 & 1,41 \\
\hline \multicolumn{8}{|l|}{ DEBICAGENS (D): } \\
\hline Sem debicagem (Testem.) & 124,00 & 55,31 & $82,57^{\mathrm{B} 2}$ & 120,50 & 4,12 & 2,18 & 1,45 \\
\hline Sem $2^{\mathrm{a}}$ debicagem & 128,00 & 53,75 & $83,58^{\mathrm{AB}}$ & 122,87 & 4,76 & 2,19 & 1,41 \\
\hline $2^{\mathrm{a}}$ debicagem na $8^{\mathrm{a}}$ semana & 126,50 & 54,06 & $84,06^{\mathrm{AB}}$ & 130,50 & 4,10 & 2,16 & 1,40 \\
\hline $2^{\mathrm{a}}$ debicagem na $10^{\mathrm{a}}$ semana & 126,75 & 54,06 & $85,25^{\mathrm{ab}}$ & 129,13 & 3,76 & 2,13 & 1,38 \\
\hline $2^{\mathrm{a}}$ debicagem na $12^{\mathrm{a}}$ semana & 129,75 & 53,18 & $87,46^{\mathrm{ab}}$ & 131,25 & 4,04 & 2,19 & 1,37 \\
\hline $2^{\mathrm{a}}$ debicagem na $14^{\mathrm{a}}$ semana & 127,75 & 53,09 & $88,54^{\mathrm{a}}$ & 128,63 & 4,00 & 2,20 & 1,40 \\
\hline \multicolumn{7}{|l|}{ VALORES DO TESTE F: } & $0,45^{\mathrm{NS}}$ \\
\hline DEBICAGENS (D) & $1,24^{\text {ns }}$ & $1,16^{\mathrm{ns}}$ & $3,70 * *$ & $1,59^{\mathrm{NS}}$ & $0,40^{\mathrm{NS}}$ & $0,25^{\mathrm{NS}}$ & $1,33^{\mathrm{NS}}$ \\
\hline INTERAÇÃO (LXD) & $0,99^{\mathrm{ns}}$ & $0,90^{\mathrm{ns}}$ & $2,10^{\mathrm{ns}}$ & $2,32^{\mathrm{NS}}$ & $0,65^{\mathrm{NS}}$ & $1,49^{\mathrm{NS}}$ & $1,71^{\mathrm{NS}}$ \\
\hline $\mathrm{CV}(\%)$ & 3,82 & 3,81 & 4,01 & 7,74 & 35,72 & 6,25 & 4,88 \\
\hline
\end{tabular}

${ }^{1}$ Dados transformados em $\operatorname{arcsen}\{(x) / 100\}^{0,5} 2$ - Médias seguidas de letras iguais nas colunas não diferem entre si (P>0,05) pelo teste de Tukey.

** Significativo $(\mathrm{P}<0,01) . \quad *$ Significativo $(\mathrm{P}<0,05)$

ns - Não significativo

porcentagem de postura, as aves debicadas com 14 semanas de idade apresentaram maior produção de ovos $(\mathrm{P}<0,01)$ quando comparadas às não debicadas durante toda a fase experimental, não ocorrendo diferença para as demais aves envolvidas. SAKOMURA et al. (1997) reportaram que aves debicadas três vezes tiveram uma produção de ovos inferior às aves não debicadas e/ou debicadas duas vezes até a 25 " semana de idade; no entanto, não foi observado efeito da debicagem sobre a produção de ovos a partir da 26' semana de idade. Por outro lado, CAREY \& LASSITER (1995), trabalhando com diferentes esquemas de debicagens, não encontraram diferenças entre os tratamentos para a produção de ovos.

Apesar de não haver diferença significativa $(\mathrm{P}>0,05)$ para a idade à maturidade sexual, observou-se que as aves não debicadas adiantaram o início da produção de ovos em aproximadamente seis dias quando comparadas àquelas debicadas. ANDRADE \& CARSON (1975) e SAKOMURA et al. (1997) verificaram um atraso de cinco dias na maturidade sexual em aves debicadas. Provavelmente, esses resultados estejam relacionados à redução no consumo de ração por parte das aves debicadas. Nesse sentido, foi relatado por ZUIN (1996) que aves da linhagem LSL, não debicadas, atingiram a maturidade sexual mais precocemente $\mathrm{e}$ consumiram mais ração quando comparadas às aves debicadas. Não foi verificada interação significativa entre linhagens e idade de debicagem para nenhum dos parâmetros de desempenho estudados.

\section{CONCLUSÕES}

Os resultados evidenciam que o desempenho produtivo é mais influenciado pela linhagem do que pela idade de debicagem. Além disso, a prática da debicagem melhora a produção de ovos, independente da linhagem.

\section{REFERÊNCIAS BIBLIOGRÁFICAS}

ANDRADE, A.N., CARSON, J.R. The effect of age and methods of debeaking on future performance of White Leghom pullets. Poultry Science, v.54, n.3, p.666-674,1975.

BANZATTO, D.A., KRONKA, S.N. Experimentação agrícola. 3 ed. Jaboticabal: FUNEP, 1995. 247p.

BECKMAN, B. Debicagem. m: SIMPÓSIO TÉCNICO DE PRODUÇÃO DE OVOS, 1994, São Paulo. Anais... São Paulo : APA, 1994. 194p. p.1 17-121.

BELL, D. the merits of beak trimming. Intemational Poultry Production, v.4, n.4, p.34,1996.

BREWARD, J., GENTLE, M.J. Neuroma formatíon and abnormal efferent nerve dischanges after partial beak amputation 
(beak trimming) in poultry. Experientia, v.41, n.10, p.11321134,1985 .

CAREY, J.B., LASSITER, B.W. Influences of age at final beak trim on the productive performance of commercial layers. Poultry Science, v.74, n.4, p.615-619,1995.

CRAIG, J.V., CRAIG, J.A., MILLIKEN, G.A. Beak trimming effects on beak lenght and feed usage for growth and egg production. Poultry Science, v.71,n.12,p.1830-1841-, 1992.

GENTLE, M.J. Beak trimming $\mathrm{m}$ poultry. World's Poultry Science Journal, v.42, n.3, p.268-275,1986.

GENTLE, M.J. HUGHES, B.O., FOX, A., et al. Behavioural and anatomical consequences of two beak trinuning methods in 1and 10-d-old domestic chicks. British Poultry Science, v.38, n.5, p.453-463,1997.

ISA. Isa Babcock B300:guia de manejo. Ithaca, NY, 1990. 23p.

LEE, K. Long tenn effects of Marek's disease vaccination with cell-free herpesvirus of turkey and age at debeaking on performance and mortality of White Leghoms. Poultry Science, v.59,n.9,p.2002-2007,1980.

LEE, H.Y., CRAIG, J.V. Beak trimming effects on behavior and weight gain of floor-reared, egg-strain pullets from three genetic stocks during the rearing period. Poultry Science, v.69, n.4, p.568-575, 1990 .

LEE, H.Y., CRAIG, J.V. Beak trinuning effects on behavior pattems, fearfülness, feathering, and mortality among three
White Leghom pullets in cage or floor pens. Poultry Science, v.70, n.2, p.211-212,1991.

LOHMANN L.S.L. Manual de criação e manejo. Uberlândia, MG:s.d. 24p.

MORENO, S.Q. Efeito da debicagem e do enriquecimento ambiental no desempenho e na frequência de bicadas por galinhas Hy-Line White mantidas em gaiolas. Jaboticabal, 1994. 52p. (Trabalho de graduação em Zootecnia) - UNESPJaboticabal, 1994.

MUIR W.M., CRAIG, J.V. Improving animal well-being through genetic selection. Poultry Science, v.77, n.12, p.1781-1788, 1998.

ROSTAGNO, H.S., SILVA, D.J., COSTA.P.M.A., et al. Composição de aumentos e exigências nutricionais de aves e suínos. Viçosa : UFV, 1987. 59p. (Tabelas Brasileiras).

SAKOMURA, N.K., MORENO, S.Q., PARANHOS DA COSTA, M.J.R., et al Efeito da debicagem e do enriquecimento ambiental no desempenho de galinhas poedeiras. Ars Veterinária, v.13, n.1, p.59-67,1997.

WELLS, D. Beak trinuning: is it really necessary? Worid Poultry, June,p.28-31, 1983.

ZUIN, L.F.S. Efeito da debicagem e do enriquecimento ambiental sobre o comportamento e a produção de galinhas da linhagem LOHMANN. Jaboticabal, 1996. 44 p. (Trabalho de graduação em Zootecnia), UNESP- Jaboticabal. 